\title{
Egg Labeling Methods for Gastric Emptying Scintigraphy Are Not Equivalent in Producing a Stable Solid Meal
}

\author{
Linda C. Knight ${ }^{1}$, Steven Kantor ${ }^{1,2}$, Siva Doma ${ }^{2}$, Henry P. Parkman ${ }^{2}$, and Alan H. Maurer ${ }^{1}$ \\ ${ }^{I}$ Division of Nuclear Medicine, Department of Radiology, Temple University School of Medicine and Hospital, Philadelphia, \\ Pennsylvania; and ${ }^{2}$ Section of Gastroenterology, Department of Medicine, Temple University School of Medicine and Hospital, \\ Philadelphia, Pennsylvania
}

\begin{abstract}
A wide range of radiolabeled test meals have been used for gastric emptying scintigraphy. The purpose of this study was to test whether $99 \mathrm{mTc}$-sulfur colloid-labeled liquid egg white is as stable as 2 fresh whole eggs labeled with 99mTc-sulfur colloid and whether the cooking method is important. Methods: Whole eggs and liquid egg white were mixed with $99 \mathrm{mTc}$-sulfur colloid and cooked by either microwaving or frying on a griddle. The cooked eggs were tested for breakdown after 2 and $4 \mathrm{~h}$ of incubation in gastric fluid or $\mathrm{HCl}$. Results: Labeled liquid egg white, prepared by either method of cooking, exhibited less breakdown in gastric fluid than whole eggs. Whole eggs cooked in the microwave exhibited significantly more breakdown than liquid egg white. Conclusion: ${ }^{99 m T c-S u l f u r ~ c o l l o i d ~ b i n d s ~ b e t t e r ~ t o ~ e g g ~ w h i t e s ~}$ compared with whole eggs. These results emphasize the need to evaluate the stability of new radiolabeled test meal preparations, including the method of cooking.
\end{abstract}

Key Words: gastric emptying; radiolabeled solid meal; $99 \mathrm{mTc}-$ sulfur colloid

J Nucl Med 2007; 48:1897-1900

DOI: 10.2967/jnumed.107.044636

G astric emptying scintigraphy to measure the emptying of a radiolabeled meal has become the gold standard for assessing gastric motility. Historically, many facilities performing this test have standardized their own test meals. Although published guidelines for performing gastric emptying scintigraphy include examples of acceptable radiolabeled solid meals, no discussion or recommendation of cooking methods is included (1). Recently, however, there has been an attempt to develop a standard meal that could enable comparison of gastric emptying data obtained at various facilities (2). This meal, which uses a commercially available liquid egg white has been adopted recently

\footnotetext{
Received Jun. 26, 2007; revision accepted Aug. 18, 2007.

For correspondence or reprints contact: Linda C. Knight, PhD, Temple University, Pharmacy Bldg., Room B-49, 3307 N. Broad St., Philadelphia, PA 19140.

E-mail: Lknight@temple.edu

COPYRIGHT @ 2007 by the Society of Nuclear Medicine, Inc.
}

as the recommended standard meal in a consensus guideline on gastric emptying scintigraphy by the Society of Nuclear Medicine and the American Neurogastroenterology and Motility Society (3).

Our facility had consistently used a meal that included 2 whole fresh eggs, beaten and mixed with ${ }^{99 \mathrm{~m} T c-s u l f u r}$ colloid $\left({ }^{99 \mathrm{~m}} \mathrm{Tc}-\mathrm{SC}\right)$ and then cooked on a griddle. We considered replacing this labeled egg mixture with Tougas et al.'s international standard low-fat recommendation of $120 \mathrm{~mL}$ of the commercially available egg substitute, mixed with ${ }^{99 \mathrm{~m}} \mathrm{Tc}-\mathrm{SC}$ and cooked in a microwave oven (4).

The purpose of this study was to test whether the commercially available egg substitute labeled with ${ }^{99 \mathrm{~m}} \mathrm{Tc}-$ $\mathrm{SC}$ and cooked in the microwave oven is as stable as 2 fresh whole eggs labeled with ${ }^{99 \mathrm{~m}} \mathrm{Tc}-\mathrm{SC}$ and cooked on a griddle.

\section{MATERIALS AND METHODS}

\section{Egg and Label Composition}

Whole Egg Meal. Two fresh large eggs were transferred from their shells to a cup and then beaten for 1 min with a plastic spoon until the yolks and whites were blended. ${ }^{99 \mathrm{~m}} \mathrm{Tc}-\mathrm{SC}$ ( $4.6 \mathrm{MBq}, 125$ $\mu \mathrm{Ci}$ ) was mixed with the eggs. This mixture was cooked either by griddle or by microwave.

Commercially Available Egg Substitute Meal. The egg substitute (EggBeaters; ConAgra Brands, Inc.) is composed of pasteurized egg whites colored with $\beta$-carotene and does not contain fat or yolks. One portion $(120 \mathrm{~mL})$ of the egg substitute, equivalent to 2 large whole eggs, was mixed in a cup with $4.6 \mathrm{MBq}$ of ${ }^{99 \mathrm{~m}} \mathrm{Tc}-\mathrm{SC}$ by stirring with a plastic spoon. This mixture was cooked either by griddle or by microwave.

\section{Cooking Method}

For griddle cooking, a nonstick electric griddle was sprayed with nonstick cooking spray and heated to medium heat. The egg/ $/ 99 \mathrm{~m} \mathrm{Tc}$-SC mixture was poured onto the pan and cooked to a firm consistency, turning the egg to ensure complete cooking.

For microwave cooking, the egg/ $/ 99 \mathrm{~m} \mathrm{Tc}-\mathrm{SC}$ mixture was mixed in a microwave-safe disposable cup (10-oz capacity), which was then microwaved at high power for $2 \mathrm{~min}$, with stirring after $1 \mathrm{~min}$ (2). 


\section{Stability Test Method}

Each labeled egg preparation was transferred to a plate and allowed to cool to room temperature. Portions of cooked egg weighing about $0.5 \mathrm{~g}$ each were placed in glass vials. Each portion was chopped to approximately 3 - to $5-\mathrm{mm}$ pieces with a metal spatula to simulate chewing. To each portion was added $1.25 \mathrm{~mL}$ of human gastric fluid $(\mathrm{pH} 1.5)$ from human subjects undergoing elective endoscopy or $1.25 \mathrm{~mL}$ of $0.032 \mathrm{M} \mathrm{HCl}(\mathrm{pH} 1.5)$. Each procedure was performed in triplicate. The vials $(24$ with each solution) were capped and placed in a water bath at $37^{\circ} \mathrm{C}$ with orbital shaking at $200 \mathrm{rpm}$ for up to $4 \mathrm{~h}$.

For each vial, a filter was prepared from a $3-\mathrm{mL}$ syringe barrel packed with a plug of surgical gauze (double thickness of 1-in. square gauze). Before use, the filter was wetted with $0.5 \mathrm{~mL}$ of $1 \%$ bovine serum albumin in isotonic saline; this was followed by a rinse of $1 \mathrm{~mL}$ of isotonic saline. In a single separate experiment, it was found that $<5 \%$ of ${ }^{99 \mathrm{~m}} \mathrm{Tc}-\mathrm{SC}$ bound to the gauze after albumin pretreatment.

At 2 and $4 \mathrm{~h}$, egg and digesting solution were transferred to the prepared filter to separate solids from liquids. The vial was rinsed once with $1 \mathrm{~mL}$ of isotonic saline and this rinse was poured through the filter. The filtrate, rinse, and gauze with egg solids were counted separately for ${ }^{99 \mathrm{~m}} \mathrm{Tc}$ content in a well counter.

After counting, the extent of cloudiness from small particulates was assessed in filtrates (gastric fluid incubations only). This was done by measuring the light transmittance at $600 \mathrm{~nm}$ in a spectrophotometer.

\section{Data Analysis}

The values for triplicate samples in a group were compared with the values for another group by unpaired $t$ test.

\section{RESULTS}

The appearance of the cooked egg preparations differed from each other (Fig. 1). After cooking, the egg substitute

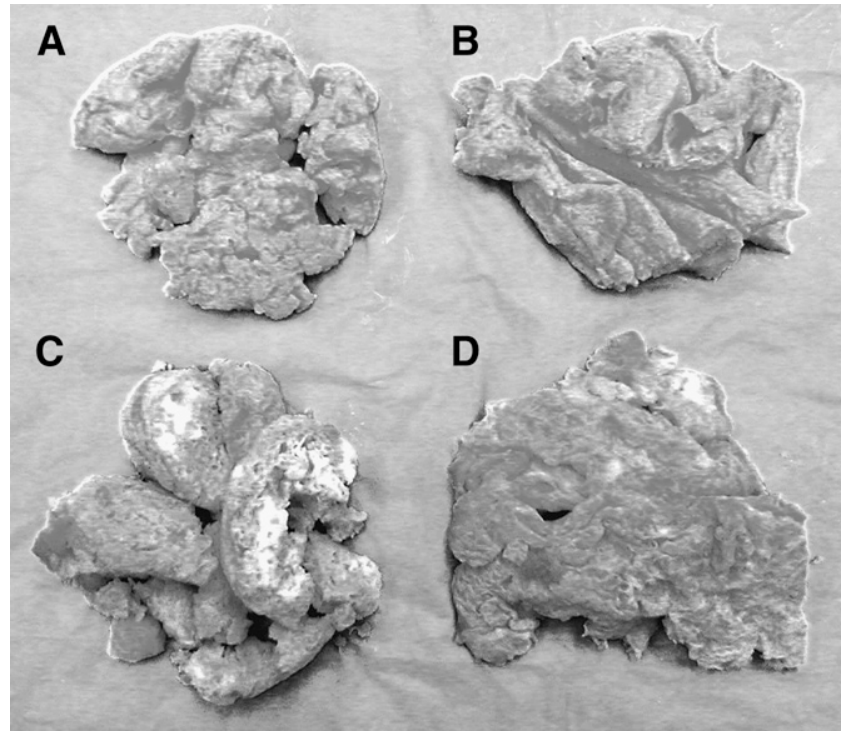

FIGURE 1. Photograph of labeled eggs showing differences in homogeneity. (A) Egg substitute cooked in microwave. (B) Egg substitute cooked on griddle. (C) Whole eggs cooked in microwave. (D) Whole eggs cooked on griddle. prepared by either microwaving or frying was homogeneous and rubbery. The fresh whole eggs cooked by frying had areas of inhomogeneity (narrow streaks of white). In contrast, the fresh whole eggs cooked by microwaving had very pronounced separate areas of white and yellow, with the white areas appearing to be one third to one half the volume of the cooked product. For the stability evaluation, care was taken to obtain a representative sample of both yellow and white areas of cooked egg.

The results of filtering the egg digests are given in Table 1 . In gastric fluid, the egg substitute prepared by either griddle or microwave was quite stable, with $>95 \%$ of ${ }^{99 m} \mathrm{Tc}$ remaining with the egg solids on the filter. Whole eggs, however, exhibited breakdown. After $2 \mathrm{~h}$ of incubation, whole eggs cooked on a griddle had significantly more decomposition than the egg substitute cooked on a griddle $(P<0.05)$. After $4 \mathrm{~h}$ of incubation, the difference did not reach significance $(P=0.14)$. Microwaved whole eggs exhibited even more breakdown at these times $(P<0.05$ at $2 \mathrm{~h}$ and $P<0.00005$ at $4 \mathrm{~h}$ compared with microwaved egg substitute at the same times). After $4 \mathrm{~h}$ of incubation, microwaved whole egg had broken down significantly more than griddle-cooked whole egg $(P<0.05)$. There was large variance among the samples of whole egg in gastric fluid, perhaps because of the heterogeneity of the cooked whole egg and the inherent friability of egg yolk. None of the preparations broke down appreciably in dilute $\mathrm{HCl}$.

In gastric fluid, whole eggs tended to disintegrate into a milky suspension. This was more pronounced with microwaved whole eggs than with griddle-cooked whole eggs. In contrast, the egg substitute (cooked by either method) remained relatively intact in chunks, and the solution did not become cloudy. This qualitative observation is substantiated by the light transmittance measurements (Table 2), which indicate that the fresh eggs disintegrated into a fine suspension much more than the egg substitute.

\section{DISCUSSION}

Unlike most nuclear medicine procedures in which unit doses of prepared radiopharmaceuticals can be ordered from an outside provider, test meals for gastric emptying scintigraphy must be prepared in the nuclear medicine department. In a busy department, there is a need to make the preparation of such meals as rapid and convenient as possible. This must be balanced with validated meals, which give reliable binding and, therefore, accurate tracing of the solid component of the meal. In addition, the meal must be sufficiently palatable to be consumed entirely by a patient with gastroparesis. Many hospitals have adopted ${ }^{99 \mathrm{~m}} \mathrm{Tc}-\mathrm{SC}-$-labeled eggs (served with toasted bread) as an acceptable test meal for their studies.

One concern with eggs as the main protein component of the meal is that cooked eggs are easily broken down to small particles that may empty as liquid. Many hospitals use radiolabeled egg meals, however, because of availability, 
TABLE 1

Percentage of ${ }^{99 m}$ Tc Remaining with Solid Egg

\begin{tabular}{|c|c|c|c|}
\hline Egg type & Method of cooking & $\%$ Solids at $2 \mathrm{~h}$ & $\%$ Solids at $4 \mathrm{~h}$ \\
\hline \multicolumn{4}{|c|}{ Incubation in human gastric fluid, $\mathrm{pH} 1.5$} \\
\hline Egg substitute & Griddle & $95.7 \pm 1.1$ & $96.4 \pm 0.8$ \\
\hline Whole eggs & Griddle & $85.8 \pm 5.3\}^{*}$ & $80.7 \pm 19.0$ \\
\hline Egg substitute & Microwave & $95.4 \pm 1.6$ & $96.2 \pm 1.1\}+$ \\
\hline Whole eggs & Microwave & $73.1 \pm 12.4\}^{*}$ & $42.5 \pm 2.3\}+J$ \\
\hline \multicolumn{4}{|c|}{ Incubation in $\mathrm{HCl}, \mathrm{pH} 1.5$} \\
\hline Egg substitute & Griddle & $96.0 \pm 3.0$ & $95.5 \pm 1.7$ \\
\hline Whole eggs & Griddle & $97.4 \pm 0.3$ & $97.9 \pm 0.5$ \\
\hline Egg substitute & Microwave & $96.0 \pm 2.9$ & $95.2 \pm 1.2$ \\
\hline Whole eggs & Microwave & $96.9 \pm 0.6$ & $97.3 \pm 0.7$ \\
\hline $\begin{array}{l}{ }^{*} P<0.05 \text { (by u } \\
{ }^{\dagger} P<0.00005\end{array}$ & & & \\
\hline
\end{tabular}

convenience, and patient acceptance. In prior direct comparisons of gastric emptying, a meal of labeled whole eggs (fried) served with toast exhibited emptying curves that were very similar to labeled chicken liver chunks in beef stew (5). A recent study showed that labeled egg substitute (cooked in a microwave) served with bread and jam had emptying curves that were similar to a labeled liver meal except at later time points (2).

The data from this study suggest that the egg substitute, when cooked either in a microwave oven or fried, has a firmer consistency that resists the tendency to disintegrate into small fragments when compared with fresh whole eggs. The egg substitute is largely egg white without fat or yolks. On the other hand, the whole eggs (white plus yolk) had a tendency to disintegrate when mixed together. This was likely related to the presence of the yolk, as the disintegration was more pronounced with the microwaved whole eggs in this study, which were very heterogeneous with large areas of yellow yolk separated from the egg white. ${ }^{99 \mathrm{~m}} \mathrm{Tc}-\mathrm{SC}$ is believed to bind to egg white protein as it becomes denatured during cooking. Adequate cooking appears to be necessary to achieve a stable label. There is no evidence that egg yolk, which is primarily fat, binds

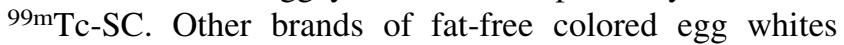
should be similarly tested for label stability.
When whole eggs were cooked by frying, they appeared to remain more homogeneous than whole eggs that were cooked by microwaving. This difference may be related to the nonuniform heating in the microwaved eggs, which allowed the albumin to separate from the yolks during the cooking process. When the eggs are fried on a griddle or in a skillet, the layer of liquid egg is relatively thin and is in contact with a higher temperature surface, which denatures the egg more quickly. It is conceivable that the microwaved whole eggs would separate less during cooking if they had been more vigorously beaten before cooking, but this was not tested to keep the procedure simple.

The stability data found in this study are in agreement with previously published data for ${ }^{99 \mathrm{~m}} \mathrm{Tc}-\mathrm{SC}$-labeled whole eggs that were fried $(5,6)$ and egg whites that were fried (7) or microwaved (4).

\section{CONCLUSION}

The following conclusions resulted from this study. (a)

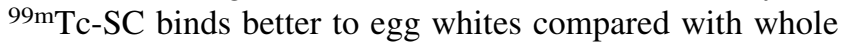
eggs. (b) The stability of a radiolabeled solid test meal for gastric emptying studies must be established both for its constituents and for the method of preparation. (c) $\mathrm{HCl}$ is not an adequate substitute for gastric fluid for testing radiolabel binding to solid food.

TABLE 2

Cloudiness of Filtrates After Incubation in Gastric Fluid Measured as \% Light Transmission (\% T) at $600 \mathrm{~nm}$

\begin{tabular}{|c|c|c|c|}
\hline Egg type & Method of cooking & $\% \mathrm{~T}$ at $2 \mathrm{~h}$ & $\% \mathrm{~T}$ at $4 \mathrm{~h}$ \\
\hline $\begin{array}{l}\text { Egg substitute } \\
\text { Egg substitute } \\
\text { Whole egg } \\
\text { Whole egg }\end{array}$ & $\begin{array}{l}\text { Griddle } \\
\text { Microwave } \\
\text { Griddle } \\
\text { Microwave }\end{array}$ & $\left.\begin{array}{r}75.1 \pm 11.5 \\
79.8 \pm 17.6 \\
5.6 \pm 0.8 \\
4.2 \pm 0.5\end{array}\right\} *$ & $\left.\begin{array}{c}69.5 \pm 12.1 \\
70.1 \pm 17.8 \\
5.5 \pm 1.5 \\
4.5 \pm 0.9\end{array}\right\}$ \\
\hline
\end{tabular}




\section{REFERENCES}

1. Donohoe KJ, Maurer AH, Ziessman HA, Urbain J-LC, Royal HD, Martin-Comin J. Society of Nuclear Medicine Procedure Guideline for Gastric Emptying and Motility. Version 2.0, approved June 6, 2004. Reston, VA: Society of Nuclear Medicine; 2004.

2. Tougas G, Chen Y, Coates G, et al. Standardization of a simplified scintigraphic methodology for the assessment of gastric emptying in a multicenter setting. Am $J$ Gastroenterol. 2000;95:78-86.

3. Abell TL, Camilleri M, Donohoe K, et al. Consensus recommendations for gastric emptying scintigraphy: a joint report of the American Neurogastroenterology and Motility Society and the Society of Nuclear Medicine. Am J Gastroenterol. In press.
4. Tougas G, Eaker EY, Abell TL, et al. Assessment of gastric emptying using a low fat meal: establishment of international control values. Am J Gastroenterol. 2000;95:14561462.

5. Knight LC, Fisher RS, Malmud LS. Comparison of solid food markers in gastric emptying studies. In: Raynaud C, ed. Nuclear Medicine and Biology Advances. Vol. III. Paris, France: Pergamon Press; 1982:2407-2410.

6. Thomforde GM, Brown ML, Malagelada J-R. Practical solid and liquid phase markers for studying gastric emptying in man. J Nucl Med Technol. 1985;13: $11-14$.

7. Kroop HS, Long WB, Alavi A, Hansell JR. Effect of water and fat on gastric emptying of solid meals. Gastroenterology. 1979;77:997-1000. 